\title{
HOUSEHOLD ELECTRICITY USAGE OPTIMIZATION USING MPC AND MIXED INTEGER PROGRAMMING
}

\author{
${ }^{1}$ Salma TAIK $*{ }^{2}$ Bálint KISS \\ ${ }^{1,2}$ Department of Control Engineering and Information Technology, Faculty of Electrical \\ Engineering and Informatics, Budapest University of Technology and Economics \\ Müegyetem rkp. 3, H-1111 Budapest, Hungary, e-mail: '1 staik@iit.bme.hu, ${ }^{2}$ bkiss@iit.bme.hu
}

Received 1 January 2019; accepted 20 May 2019

\begin{abstract}
This paper discusses the control of the electric energy consumption in a household equipped with smart devices. The household consumption pattern is the result of a two-level optimization framework. The scheduling of the electric appliances is determined by the first optimization, receiving Time of Use tariffs proposed by the utility company. The scheduler considers the consumer's preferences on the powering on for each appliance.

Secondly a model predictive controller is developed to control the electric heating system based on energy constraints resulting from the appliance scheduling.

Simulations show the energy efficiency and an optimized electricity cost of the strategy proposed.
\end{abstract}

Keywords: Smart grid, Household electricity consumption, Appliance scheduling, Optimization, Model predictive control

\section{Introduction}

Providing the sufficient electric power to the demand side to allow each household to run the appliances throughout the day may be a challenge for the utility company. Surges in consumption may require of the integration of new power generation sources, which represents an expensive solution especially if they remain unused outside the surge periods. For the power consumption side, the price of the electricity in the day remains unchangeable; therefore, an optimized electricity cost is not required. Smart grid concepts with households equipped by smart meter devices are introduced recently

\footnotetext{
${ }^{*}$ Corresponding Author
} 
[1]. The smart grid is characterized by a time-changing electricity price that may change the demand side response. Dynamic pricing strategies have been proposed earlier in [2], and several pricing schemes were developed by multiple authors: Real-Time Pricing (RTP) [3]-[6] deals with the consumer side scheduling to attend their comfort level with low electricity bills [4], Time of Use pricing (ToU) [7] balances the profits of the utility company and the consumer side, and other schemes are also discussed in [8]. The common objective of these methods is to provide an incentive to the consumers to shift their appliances' operation with higher consumption to off-peak hours [9], [10].

Consumers cannot be expected to continuously adjust their consumption to dynamical tariffs since the marginal benefit of one action is small. Hence, this process should be automated. Scheduling the smart home appliances using one or a combination of the pricing schemes has been studied previously using advanced algorithms. In [11], a fuzzy goal algorithm was discussed considering real spot prices for electricity, and the results show the adaptation of the smart appliances to the prices. Mixed Integer Linear Programming (MILP) is used in [12] to reduce the cost and the Peak-to-Average Ratio (PAR). Dynamic pricing also requires the optimization of continuously operated electric systems as the heater or A/C. Architectural solutions were proposed in [13] and [14], but the aim of this paper is to seek for controlling the home appliances by applying smart control algorithms. In [15], the household temperature was controlled using the Model Predictive Control (MPC) where the peak electricity was reduced. While in [16] an economic MPC was designed to control the building's temperature, it was also shown the ability of the algorithm to shift the loads to off-peak.

In this paper, the schedule and the control of the smart electric home appliances to ensure an optimal cost and an efficient usage of the power is tackled. For that purpose, a framework of two optimization levels is suggested under the time of use pricing schemes. The first optimization level consists of scheduling the smart appliances using the MILP, where an optimal schedule assigning each appliance's operation to a specific time. The second optimization level is reserved for the electric heating system control where an MPC was proposed, taking into consideration the results of the first optimization level as an energy constraint to intelligently consume the power available for the household energy and time constraints to achieve the comfort level set by the consumer. The paper also argues that the optimization framework proposed is practically easy to be integrated and executed by various controller platforms. In this paper, the Building Management System Controller (BMSC) is supposed to be the host of the framework proposed.

\section{The electricity consumption model of the household}

In the proposed model, the household's appliances are divided into two categories, non-thermal appliances that are either on/off or operate in a batch-like fashion e.g. dishwasher, electric vehicle, etc. and thermal appliances that function continuously based on requested performance and are susceptible to instantaneous variations in power consumption e.g. electric heating system and AC. The electricity consumption model of appliances was constructed to tackle the scheduling problem.

The non-thermal set $A$ can be further divided into two subsets depending on the operational flexibility of the appliance over the time. The shiftable appliances 
$A_{\text {shift }} \subset A$ are able to operate many times at any time of the day (e.g. washing machine). This flexible feature may enable the switching on of the appliance when the price is low. Therefore, the shiftable appliances are considered as smart or manageable by the BMSC. The non-shiftable appliances $A_{\text {nonshift }} \subset A$ are mainly the appliances operated manually by the consumer (e.g. the lights, the laptop, etc.), and the appliances that run on and off regularly depending on their own state (e.g. the refrigerator), where $A_{\text {shift }} \cap A_{\text {nonshift }}=0$ is assumed and it is supposed to be unmanageable by the BMSC.

The household envelope is assumed to be perfectly isolated where any thermal exchanges between the household rooms are neglected. Therefore, the indoor temperature in this case is considered homogeneous. The electric heating system model was based on thermal law and reads

$$
Q_{\text {heat }}=M c_{p}\left(T_{\text {heater }}-T_{\text {in }}\right) \text {, }
$$

and the overall temperature model is given as

$$
\frac{d}{d t} Q_{m}=Q_{\text {heat }}-Q_{c}-Q_{k},
$$

where $Q_{\text {heat }}$ is the heat produced by the electric heater $(\mathrm{J}) ; M$ is the air flow rate $(\mathrm{Kg} / \mathrm{min}) ; c_{p}$ is the specific heat capacity of the materiel $(\mathrm{J} / \mathrm{KgK}) ; T_{\text {heater }}$ is the temperature of the air coming out from the heater $\left({ }^{\circ} \mathrm{C}\right) ; T_{i n}$ is the household's temperature; $Q_{m}$ is the stored heat in the household; $Q_{c}$ is the conductive heat transfer and $Q_{k}$ is the heat flow by convection between the interior and exterior surface of the household. The scheduling optimization of the appliances and the control of the electric heating system are discussed in Section 3 and Section 4, respectively.

\section{The scheduling of non-thermal appliances}

The purpose of the appliance scheduling is to shift the appliances with high energy consumption to off-peak provided that the amount of available electric power is limited at any given time. As the price proposed by the utility company changes along the day, the scheduler needs to find the optimal time for operating each appliance with the aim of minimizing the energy costs. The ToU pricing scheme used in this paper is characterized by three features established based on the cost of producing electricity in the power generation side and the changes of the demand side. Off-peak designates the period with the lowest price, and on-peak designates the highest price period. The ToU pricing, denoted by the vector Price ${ }^{k}$ is considered here to be similar along the days of the week, and it represents an input to the algorithms developed later. The day is divided into time slots starting from $7 \mathrm{AM}$ to the end of the 24 hours, each time slot refers to a time interval of $\Delta t=15$ minutes. In total, the day is divided into $N_{\text {slot }}=96$ time slot. 
In this paper, the algorithm schedules the shiftable (manageable) appliances only. Let $N_{\text {app }}$ denote the number of appliances in the set $A_{\text {shift }}$. An appliance $A_{i} \in A_{\text {shift }}$ is characterized by its power vector $P_{i}$. The vector $P_{i}$ has nload $_{i}$ elements. It is supposed that the operation of the appliance is uninterruptible during nload $_{i}$ time slots. As an example, the appliance $A_{1}$ has an operation program of one hour and its power load vector is $P_{1}=[0.7,0.1,0.8,1]$, where the first load phase is $P_{1,1}=0.7$.

Every appliance operation has duration $\operatorname{Dur}_{A_{i}}=$ nload $_{i}$, and its starting time can be controlled throughout the day, and each load phase takes $\Delta t$ to run. For instance, appliance $A_{i}$ operation has an execution window of 60 minutes ( 60 minutes/15 minutes $=4$ time slots), and along this duration the load phases ( 4 load phases) are executed one by one.

The smart appliances have fixed energy consumption at each operation, and it is characterized by two states: whether the appliance is $\mathrm{ON}$ and the phases of the power load are executed sequentially during the program duration or OFF. It is supposed here that all the shiftable appliances have to be scheduled and to run one time. However if it is desired for a specific appliance to run multiple times in one day or to not be scheduled, it is sufficient to duplicate the energy consumption vector of the appliance in the appliances' set or to replace its vector by zeros. The optimization proposed in this paper is on the consumer side, precisely on the ON and OFF states of the smart appliances (shiftable/manageable). The optimization is based on the ToU electricity tariffs, while respecting every appliance's operation window as time constraints. It is also based on input data provided by the utility company; which is the energy allowed at every time slot $P_{a v}^{k}$, and the total power $P_{d a y}$ assigned to the household in 24 hours. Recall that the power limits for the time slots must be consistent with the daily power limit:

$$
\sum_{k=1}^{N_{s l o t}} P_{a v}^{k}=P_{d a y}
$$

The unmanageable appliances $A_{\text {nonshift }}$ consume a small amount of power comparing to the $A_{\text {shift }}$ set. For that, an additional fixed power vector $P_{\text {nonshift }}$ was allocated for the operation of $A_{\text {nonshift }}$ set to be consumed in 24 hours. Therefore, it is necessary to subtract it from the power available per slot $P_{a v}^{k}$.

The scheduler has to determine the switching on time of the appliances, and the resulting energy consumption schedule of the appliance is denoted by

$$
P_{\text {appliances }}^{k}=\sum_{i=1}^{N_{\text {app }}} P_{i}^{k}+P_{\text {nonshift }}^{k}, \quad \forall k=\left[1, \cdots, N_{\text {slot }}\right],
$$




\subsection{Decision variables}

Let the binary decision variable, $O N_{i, j}^{k}$, indicates the state of appliance $A_{i} \in A_{\text {shift }}$ during the load phase of operation $j$ in the time slot $k \in\left[1, \cdots, N_{s l o t}\right] . O N_{i, j}^{k}=1$ means that the appliance is switched on. A complementary variable $\overline{O N}=O F F$ is introduced, where $O F F_{i, j}^{k}=1$ indicates that the phase $j$ of the appliance $A_{i}$ is already finished in the time slot $k$. It means that whether $O N=1$ or $O F F=1$ at the time slot $k$, and the sum of these variables should be at every scheduled time slot

$$
O N_{i, j}^{k}+O F F_{i, j}^{k}=1 \text {. }
$$

\subsection{Constraints}

When the appliance $A_{i}$ is operated, all load phases of $A_{i}$ should be in $O N$ state. Therefore, the decision variable $O N_{i, j}^{k}$ should be 1 for all $j \in\left[1, \cdots\right.$, nload $\left._{i}\right]$, which implies that

$$
\sum_{j=1}^{\text {nload }_{i}} \text { ON }_{i, j}^{k}=\text { nload }_{i} .
$$

The load phases of the same appliance are uninterruptible and executed sequentially. This constraint reads

$$
O N_{i, j}^{k-1}-O N_{i, j}^{k} \leq O F F_{i, j}^{k}
$$

The energy consumed by the appliance $A_{i}$ in each time slot $k$ of should not exceed the power available during the time slot $k$. Moreover, the total energy consumed by the appliances in 24 hours should not exceed $P_{d a y}$. These constraints read:

$$
\begin{aligned}
& \sum_{i=1}^{N_{\text {app }}} \sum_{j=1}^{\text {nload }_{i}} P_{i, j}^{k} \leq P_{a v}^{k}-P_{\text {nonshift }}^{k}, \\
& \sum_{i=1}^{N_{\text {app }}} \sum_{j=1}^{\text {nload }_{i}} P_{i, j}+P_{\text {nonshift }} \leq P_{\text {day }} .
\end{aligned}
$$

To schedule the appliances, additional constraint are taken into account since the consumer may specify the earliest switching on and the latest switching off times of the shiftable appliance, denoted time $_{O N}$ and time $_{O F F}$ respectively:

$$
\text { time }_{O F F, i}-\text { time }_{O N, i} \geq \operatorname{Dur}_{A i},
$$




$$
\text { time }_{O N, i} \leq\left\{k: O N_{i, 1}^{k}=1\right\}, \quad\left\{k: \text { ON }_{i, \text { nload }_{i}}^{k+\text { nload }_{i}-1}=1\right\} \leq \text { time }_{O F F, i} .
$$

\subsection{The cost function}

The optimal electricity cost of the power consumed by the household's appliances in 24 hours is formulated as follow:

$$
J=\min _{O N} \sum_{k=1}^{N_{\text {slot }}} \text { Price }^{k}\left(\sum_{i=1}^{N_{\text {app }} \text { nload }_{i}} \sum_{j=1} O_{i, j}^{k}\right),
$$

by optimizing the cost function (12) subject to constraints (3)-(11), an optimal schedule of the household's appliances operation for one day is allocated, and the optimal starting times will be transferred to the smart appliances by the BMSC.

\section{The electric heating system control}

For the sake of simplicity, an electric heating system in the household is considered. An air conditioning (i.e. cooling) system tackled following the same ideas. The consumption of the electric heating system discussed in this paper is bounded by a minimal and maximal power consumption bounds as in [17]. This interval determines the amount of power that may be consumed in each time slot by the heating system. The power interval for the smart electric heating system operation is denoted by $0 \leq P_{\text {heater }} \leq P_{\max }$, where $P_{\text {heater }}$ is the actual consumed power of the actuated electric heating system, $P_{\max }$ is the maximum nominal power consumption of the heating system and it is determined by the technical specifications of the electric heating system.

Scheduling the ON and OFF type home appliances leaves a power margin $P_{\text {margin }}$ for the operation of the heating system in the household. In this paper, the power margin is limited by $P_{a p p l i a n c e s}^{k}<P_{\text {margin }}^{k} \leq P_{a v}^{k}$ and contains the future $P_{\text {heater }}$ controlled to achieve a certain required performance.

To cope with the thermal dynamics of the household temperature, with dynamical constraints of the input and with dynamic ToU pricing as well, a real-time control is necessary to fulfill the task. Therefore, an MPC was developed and a closed loop control problem is formulated where the temperature of the household is the controlled variable and it is fed back to the MPC with the aim of reaching the comfort level desired by the consumer.

The MPC algorithm is developed to control the power of the electric heating system to maintain its consumption in its power interval and on the consumption $P_{\text {appliances }}$ of the non-thermal appliances obtained by the optimal scheduling. The MPC receives the ToU tariffs Price $^{k}$, the actual temperature of the household $T_{i n}$, and the power consumed by the non-thermal appliances $P_{\text {appliances. }}$ The MPC performs an 
optimization at every sample time $T_{S}=15$ minutes, in order to get to drive $T_{i n}$ to the desired temperature $T_{\text {desired }}$ along the prediction horizon $N_{\text {prd }}=10$ such that the heating (i.e. actuation) cost and the temperature cost are minimal. This is actually a second optimization after the scheduling. The process is carried out by applying the first input sample and then shifting the prediction horizon. The cost function minimized by the MPC reads

$$
J_{2}=\min _{P_{\text {heater }}} \sum_{k=1}^{N_{\text {prd }}} P_{\text {heater }} \cdot \text { Price }^{k}+\sum_{k=1}^{N_{\text {prd }}}\left(T_{\text {in }}^{k}-T_{\text {desired }}\right)^{2} .
$$

The power consumed by the electric heating system is constrained by

$$
\begin{aligned}
& P_{\text {heater }}^{k} \leq P_{\text {av }}^{k}-P_{\text {appliances }}^{k}, \\
& P_{\text {total }} \leq P_{\text {day }},
\end{aligned}
$$

where $P_{\text {total }}$ designates the total power consumption of all the appliances of the household. And the output constraint reads

$$
T_{\min }=22 \leq T_{\text {in }} \leq T_{\max }=27 .
$$

The optimal control law will be computed at each time slot by minimizing the cost function (13) subject to constraints (3) and (14)-(16) and to the temperature dynamics of the household (1) and (2).

\section{Simulation results}

In this section, some simulation results are discussed. All simulations are executed in Matlab/Simulink R2018a. Consider $P_{a v}^{k}=5.5 \mathrm{~kW}$ and $P_{d a y}=P_{a v}^{k} \cdot N_{\text {slot }}$.

\subsection{The non-thermal appliance scheduling}

To facilitate the communication between the consumer and the optimization algorithm, a GUI was also designed offering two options. The first option is to choose the ability to assign the appliances randomly to optimal time slots. The other option is to schedule with the time constraints imposed by the consumer.

A sample household is considered where the appliances to be scheduled are $A_{\text {shift }}==$ \{washing machine, dishwasher, oven, electric car $\}$. The power consumption to charge the electric car is considered as constant during a fixed time operation window. The parameters needed for the optimal scheduler are shown in Table I. and the appliances' program can be modified.

The ToU electricity tariff Price ${ }^{k}$ is considered to be known. The scheduling optimization is solved by the YALMIP toolbox [18] available in Matlab using the GUROBI solver. The scheduling optimization took 0.14 second. Simulations are done 
in a computer with an Intel Core i5 $3 \mathrm{GHz}$, processor with $8 \mathrm{~GB}$ of RAM and Windows 10. Two scenarios is simulated and they are presented in the next subsections.

Table I

Appliances power loads with Consumer's time preferences for the appliances

\begin{tabular}{|l|l|l|l|l|}
\hline Appliance & Power Load $(\mathrm{KW})$ & Dur $_{\mathrm{Ai}}(\mathrm{min})$ & $\begin{array}{l}\text { Start } \\
\text { Time }\end{array}$ & End Time \\
\hline $\begin{array}{l}\text { Washing } \\
\text { machine }\end{array}$ & {$[0.5,0.6,0.5,0,2.9,2.9,2.9$,} & 120 & $9: 15 \mathrm{AM}$ & $2 \mathrm{PM}$ \\
$\begin{array}{l}\text { Dishwasher } \\
\text { Oven_morning }\end{array}$ & $\begin{array}{l}0.2] \\
{[1.2,1.2,0.2,1,0.8,0.8,0.6]}\end{array}$ & 105 & $7: 15 \mathrm{PM}$ & $9: 30 \mathrm{PM}$ \\
$\begin{array}{l}\text { Oven_evening } \\
{[2.35,0.8,1.3,0.8,0.75,}\end{array}$ & $\begin{array}{l}30 \\
80\end{array}$ & $\begin{array}{l}5 \mathrm{AM} \\
10: 30 \mathrm{AM}\end{array}$ & $7 \mathrm{PM}$ \\
$\begin{array}{l}\text { Electric vehicle } \\
\text { charging }\end{array}$ & $\begin{array}{l}0.75] \\
{[3,3,3,3,3,3,3,3,3,3]}\end{array}$ & 150 & $9: 45 \mathrm{PM}$ & $6 \mathrm{AM}$ \\
\hline
\end{tabular}

\section{Simulation scenario 1}

The optimal schedule of the appliances is given in Fig. 1, it illustrates the power consumption assigned at each time slot for the set $A_{\text {shift }}$. The power consumption of the smart appliances is distributed on off-peak and mid-peak period because apriority distribution of the appliances' operation was set beforehand to prevent some appliances from operating in inconvenient times. Thus, the total cost of the electricity consumed is optimal without crossing the power available for the day.
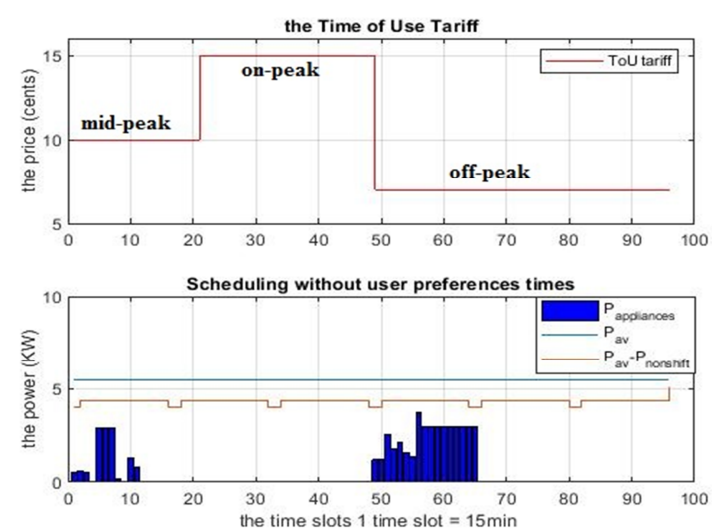

Fig. 1. Scheduling without the time preferences constraints and ToU electricity tariffs

\section{Simulation scenario 2}

The simulation results are explored in Fig. 2, which shows the optimal schedule of the appliances that is distributed based on the consumer requested time. There is only a 
part of one appliance scheduled in on-peak period and it is mainly because of the random time choices made by the consumer.
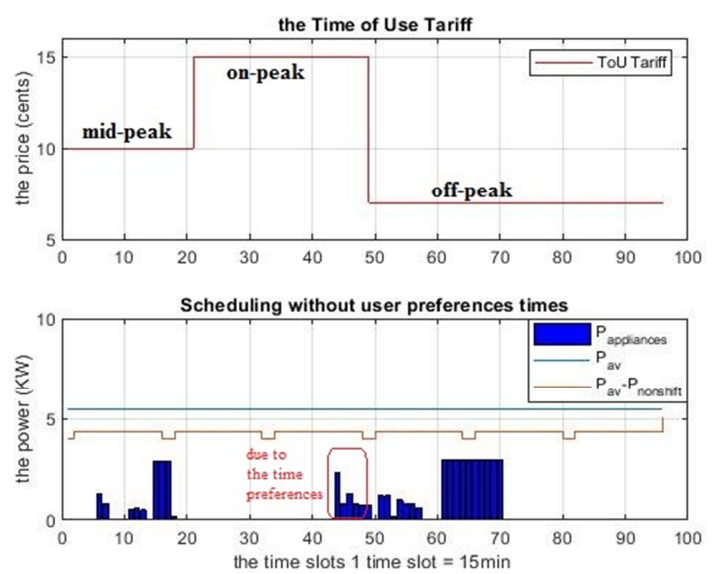

Fig. 2. Scheduling with the time preferences constraints and ToU electricity tariffs

\subsection{The electric heating system control}

This section provides the results of simulating the control of the electric heating system by the MPC. The algorithm uses the resulting power schedule $P_{\text {appliance }}$ of the smart appliances from first scenario previously presented. Where the temperature required by the consumer is $T_{\text {desired }}=25^{\circ} \mathrm{C}$, and $P_{\max }=2 \mathrm{~kW}$.

\section{Simulation scenario 1}

In Fig. 3 the electric heating system in the first slots uses the available power to reach $T_{\text {desired }}$, then adjust the power consumption to maintain the household temperature in the comfort zone bounded by $T_{\min }$ and $T_{\max }$. When the price is high, the heater uses the minimum energy to maintain $T_{\text {desired }}$ and then goes off. It also goes off when the energy available is not sufficient for its operation. Consequently, as in Fig. 4 it can be seen that the proposed method balances and economizes the total energy consumption of the household without exceeding $P_{a v}^{k}$ and $P_{d a y}$ of the household, and also allows the consumer to pay an optimal electricity cost while maintaining the requested temperature.

\section{Simulation scenario 2}

In this scenario, the power available per slot is set to $P_{a v}^{k}=4.9 \mathrm{~kW}$ to evaluate the ability of the MPC in adopting to any energy changes, even to smaller amount of energy. Fig. 5 shows the temperature in the comfort level zone and the total power 
consumption also is under the limits of $P_{a v}^{k}$, which demonstrates the ability of the MPC to adopt to the imposed energy constraints.
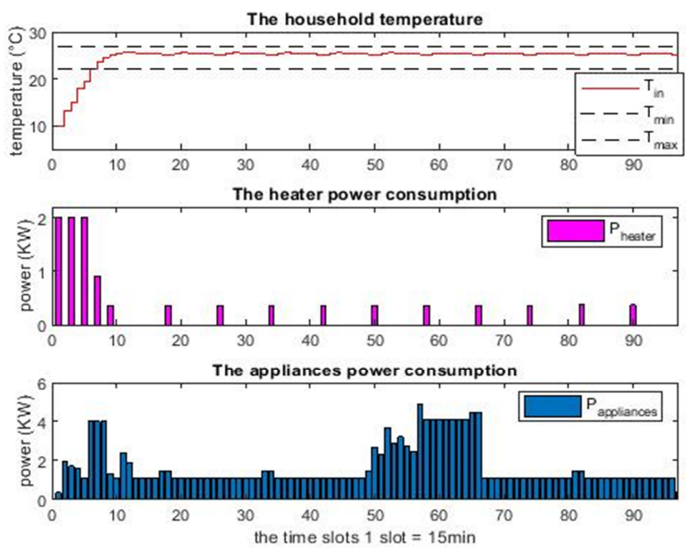

Fig. 3. The temperature of the household and the power consumption of the heating system
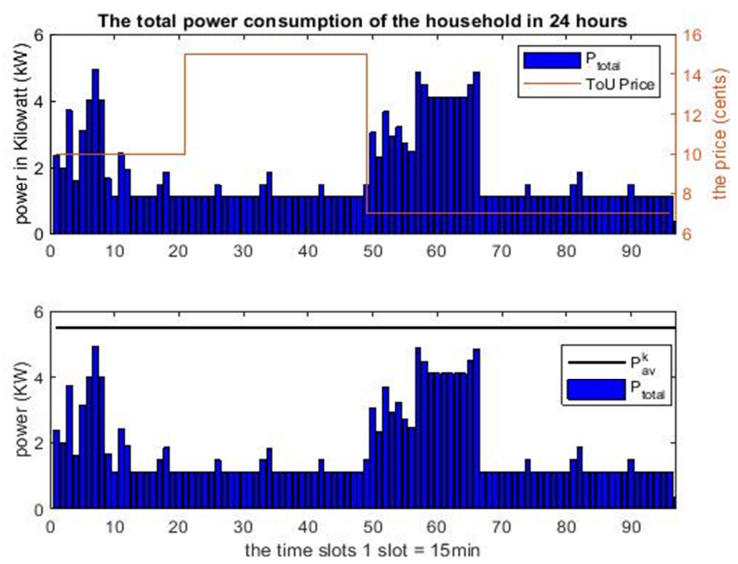

Fig. 4. The total power consumption of the household in 24 hours

\section{Conclusion}

In this paper a two-level optimization framework is suggested based on ToU tariffs to optimize the electricity cost and balance the energy consumed in a smart household. A MILP algorithm was adopted to schedule the smart appliances and an MPC-based approach was developed to control the electric heating system using its power interval feature and the resulting schedule from the first optimization level. The loads are shifted to the off-peak and the temperature of the household reached the consumer's comfort 
level and is maintained by balancing the energy available throughout the day and optimizing the total electricity cost. The framework proposed is efficient and able to shift the loads with higher consumption and demonstrates the ability of the MPC to adopt to any energy changes.
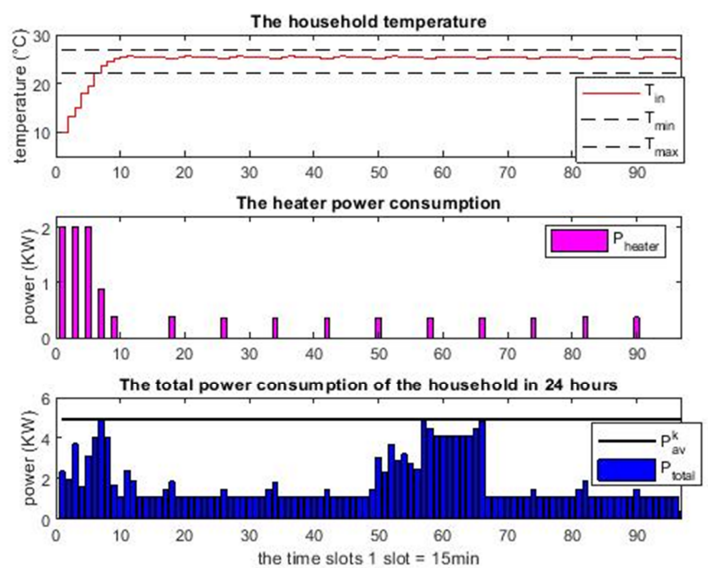

Fig. 5. The household temperature and the total power consumption in 24 hours.

In further research work, new constraints will be introduced. For instance, optimizing the energy stored in the electric vehicle's battery in charge mode and retrieving the energy from the battery when needed. Various ToU tariffs will be considered along the week, holidays, and seasons. The iteration of the two level optimization will also be developed to have efficient power consumption.

\section{Acknowledgment}

This work was supported by the Higher Education Excellence Program of the Ministry of Human Capacities in the frame of Artificial Intelligence research area of Budapest University of Technology and Economics (BME FIKP-MI/SC).

\section{Open Access statement}

This is an open-access article distributed under the terms of the Creative Commons Attribution 4.0 International License (https://creativecommons.org/licenses/by/4.0/), which permits unrestricted use, distribution, and reproduction in any medium, provided the original author and source are credited, a link to the CC License is provided, and changes - if any - are indicated. (SID_1)

\section{References}

[1] Fang X., Misra S., Xue G., Yang D.Al. Smart grid-the new and improved power grid: A survey, IEEE Comm. Survey and Tutorials, Vol. 14, No. 4, 2012, pp. 944-980. 
[2] Borenstein S., Jaske M. Rosenfield A. Dynamic pricing, advanced metering and demand response in electricity markets, The Energy Foundation, California, 2012.

[3] Jowe-Wong C., Sen S., Ha S., Chiang M. Optimized day-ahead pricing for the smart grid with device-specific scheduling flexibility, IEEE Selected Area Comm. Vol. 30, No. 6, 2012, pp. 1075-1085.

[4] Mohsenian-Rad A. H., Leon-Gercia A. Optimal residential load control with price prediction in real-time electricity pricing environments, IEEE Trans. on Smart Grid, Vol. 1, No. 2, 2010, pp. 120-133.

[5] Mohsenian-Rad A. H., Wong V. W. S., Jatskevich J., Schober R., Leon-Garcia A. Autonomous demand side management based on game-theoretic energy consumption scheduling for the future smart grid, IEEE Trans. on Smart Grid, Vol. 1, No. 3, 2010, pp. 320-331.

[6] Qian L. P., Zhang Y. J. A., Huang J., Wu Y. Demand response management via real-time electricity price control in smart grid, IEEE Selected Area in Comm. Vol. 31, No. 7, 2013, pp. 1268-1280.

[7] Braithwait S., Hansen D., O'sheasy M. Retail pricing and rate design in evolving markets, Edison Electric institute, 2007.

[8] Khan A. R., Mahmood A., Safdar A., Khan Z. A., Khan N. A. Load forecasting, dynamic pricing and DSM in smart grid: a review, Renewable and Sustainable Energy Reviews, Vol. 54, 2016, pp. 1311-1322.

[9] Ipakchi A., Albuyeh F. Grid of the future, IEEE Power and Energy Magazine, Vol. 7, No. 2, 2009, pp. 52-62.

[10] Fahrioglu M., Alvardo F. L. Designing incentive compatible contracts for effective demand managements, IEEE Trans. on Power Systems, Vol. 15, No. 4, 2000, pp. 1255-1260.

[11] Bu H., Nygard K. E., Adaptive scheduling of smart home appliances using fuzzy goal programming, The Sixth International Conference on Adaptive and Self-Adaptive Systems and Applications, Venice, Italy, 25-29 May 2014, pp. 129-135.

[12] Bozchalui M., Hashmi S. A., Hassen H., Canizares A. C., Bhattacharya K. Optimal operation of residential energy hubs in smart grids, IEEE Trans. on Smart Grid, Vol. 3, No. 4, 2012, pp. 1755-1766.

[13] Baranyai B., Kistelegdi I. Energy management monitoring and control of public buildings, Pollack Periodica, Vol. 9. No. 2, 2014, pp. 77-88.

[14] Kovari G., Kistelegdi I. Optimized building automation and control for the improvement of energy efficiency and climate comfort of office buildings, Pollack Periodica, Vol. 10. No. 1, 2015, pp. 71-82.

[15] Oldewurtel F., Ulbig A., Parisio A., Andersson G., Morari M. Reducing peak electricity demand in building climate control using reeal-time pricing and model predictive control, $49^{\text {th }}$ IEEE Conf. on Decision and Control, Atlanta, GA, USA, 15-17 December 2010, pp. 1927-1932.

[16] Halvgaard R., Poulsen N. K., Madsen H., Jørgensen J. B. Economic model predictive control for building climate control in smart grid, IEEE Conference PES Innovative Smart Grid Technologies, Washington DC, USA, 16-20 January 2012, pages 1-6.

[17] Chen C., Wang J., Heo Y., Kishore S. MPC-based appliance scheduling for residential building energy management controller, IEEE Trans. on Smart Grid, Vol. 4, No. 3, 2013, pp. 1401-1410.

[18] Löfberg J., YALMIP: A toolbox for modeling and optimization in MATLAB, IEEE International Conference on Robotics and Automation, New Orleans, LA, USA, 2-4 September 2004, Page No. 8304275. 